\title{
A INTERDISCIPLINARIDADE COMO MEDIADORA DA VERACIDADE: o diálogo sobre jornalismo, história e antropologia
}

\author{
The interdisciplinarity as a mediator of the truth: \\ dialogue on journalism, history and anthropology
}

\author{
Érika Patrícia Batista \\ Jornalista, Mestranda em Comunicação Social pela Universidade de Marília (UNIMAR), professora da Universidade da Grande \\ Dourados Centro Universitário da Grande Dourados (UNIGRAN), Dourados, MS - Brasil, e-mail: erikabatista@msn.com
}

\begin{abstract}
Resumo
Este artigo é um exercício reflexivo a respeito da necessidade da promoção de estudos interdisciplinares entre a Antropologia, História e Jornalismo. O objetivo é apontar a precisão da mediação entre essas áreas para que haja veracidade nas informações levantadas a respeito de temas complexos, como a cultura indígena, que requer uma investigação mais aprofundada. Partindo da percepção de Cremilda Medina, esboça-se sobre a necessidade de jornalistas, antropólogos e historiadores construírem um diálogo, mesmo sendo profissionais com objetivos, métodos e ações bastante distintos, a fim de complementar e enriquecer os resultados das pesquisas produzindo notícias pautadas em informações concretas vindas de fontes seguras. Como resultado, o texto mostra que é necessário permear por campos referentes aos assuntos abordados para que a interpretação desses dados seja feita de maneira confiável, mas que muitas vezes esse diálogo é dispensado, gerando resultados que omitem a verdade, o que interfere na credibilidade da informação que é produzida.
\end{abstract}

Palavras-chave: Jornalismo. Antropologia. História. Interdisciplinaridade.

\begin{abstract}
This article is a reflective exercise about the need of promotion of interdisciplinary studies involving Anthropology, History and Journalism. It aims to point the mediation precision of these areas in order to obtain veracity on the provided information about complex subjects, as the aboriginal culture, that requires a more deepened inquiry. Starting on the perception of Cremilda Medina we will sketch about the necessity of journalists, anthropologists and historians to construct a dialogue, despite being professionals with distinct objectives, methods and actions,
\end{abstract}


in order to complement and improve the results of the research, producing notices based on concrete information from safe sources. As a result, the text shows that it is necessary to permeate the fields relating to the subject matter for the interpretation of these data is done reliably, but often this dialogue is relieved leading to results that omit the truth and that interferes with the credibility of information.

Keyworks: Arquaeology. History. Journalism. Interdisciplinarity.

\section{INTRODUÇÃO}

Não se trata de uma discussão nova, a interdisciplinaridade é um tema bastante suscitado entre historiadores, antropólogos e jornalistas, no que tange ao diálogo mais centrado entre campos distintos. Essas áreas de certa forma se assemelham quanto ao uso de ferramentas de pesquisas.

Assim, o objetivo deste artigo está em salientar a necessidade de promover estudos e explorar de maneira intrínseca, outras ciências, principalmente a Antropologia, a História e o Jornalismo.

A interdisciplinaridade entre várias áreas, como Antropologia, História e Jornalismo existe, mas quando se trata de aplicabilidade ainda é escassa a parceria no processo de pesquisa científica, portanto, uma visão preconcebida assinala que a preocupação está na questão prática.

Torna-se propício traçar um paralelo e definir História, Antropologia e Jornalismo, áreas interligadas pelo âmbito da pesquisa, pela busca fidedigna do saber.

A Antropologia e o Jornalismo, Segundo Antônio Brasil (2002), são áreas que atuam de forma diferente, porém, possuem interesses comuns. Mas vale ressaltar que tal confluência ou cumplicidade pode gerar novos campos de interesse tanto para uma área como para outra, dessa forma, não existe uma ruptura epistemológica entre a sua vivência de jornalista e a sua prática como cientista social.

Portanto, jornalistas, antropólogos, historiadores e arqueólogos são profissionais com objetivos, métodos e visões de mundo bastante distintas, mas a análise construída a partir da interdisciplinaridade permite uma aproximação no ponto de vista informacional e prático, pois tal aproximação toma um caráter complementar que irá enriquecer os resultados das pesquisas.

Para abordar a relação da interdisciplinaridade e o seu aparato teórico-metodológico, os estudos partirão da Etnoistória, um estudo que possibilita a mediação entre as ciências.
Em seguida, serão apontados alguns equívocos de uso descontextualizados, em termos teóricos antropológicos, de informações para dar veracidade à pesquisa. Neste momento, surge a maior preocupação, que está relacionada às temáticas indígenas. Sobre este assunto, Roberto Cardoso de Oliveira (2005) salienta que o pesquisador, ao buscar informações em uma determinada comunidade indígena, precisará de uma percepção não ingênua sobre o assunto, pois ele encontrará diversos focos de informações e precisará interpretá-las para verificar a informação coletada.

Dessa forma, busca-se compreender até que ponto a interpretação de fatos, sem a base do conhecimento em determinadas instâncias, são capazes de prejudicar a pesquisa. Para isso, pesquisadores como Jorge Eremites de Oliveira e Roberto Cardoso de Oliveira, Pedro Paulo Funari e João Pacheco de Oliveira foram consultados.

Assim, as investigações jornalísticas são prejudicadas, por vezes, por utilizar as ferramentas históricas sem uma concepção metodológica do viés antropológico. Este tema será a pauta final deste artigo.

\section{A Interdisciplinaridade e o uso das fontes históricas em prol da pesquisa}

Quando se pronuncia a palavra História, o que vem a mente são os contos, narrativas, lembranças de fatos já ocorridos que ganharam tamanha significância que precisam ser rememorados. Mas, o que significa a palavra História? Segundo Pedro Paulo Funari (2000, p. 81), a terminologia História, originária do grego, significa 'pesquisa'. Tal definição remete a um estudo mais aprofundado quanto à denotação da palavra e sua aplicação, pois a História é um afluente de investigações, pesquisas de profissionais que analisam inúmeros elementos sejam eles, documentos, memórias, vestígios, artefatos e muitos outros índices de reconstituição de um evento 
histórico. Dessa forma, a História não tem por objetivo pesquisar somente o passado, ela é uma ciência que estuda os homens no tempo e no espaço.

O autor ainda cita Heródoto como pai da História, por ser considerado o primeiro historiador, segundo ele, as histórias, contudo, eram pesquisas, investigações sobre as coisas do presente. Sendo essa busca que ele se voltou para o passado.

Dessa forma, esta ciência abrange um amplo campo de pesquisa e resulta em vastos conhecimentos, porém, atrelados às novas abordagens vindas de outras vertentes, como a Antropologia e o Jornalismo. Para melhor compreensão da temática abordada, faz-se um breve levantamento conceitual dessas áreas.

Antropologia deriva da palavra grega anthropos que significa "homem" ou "humano" e logos que significa "pensamento, razão", portanto, a disciplina estuda as origens, o desenvolvimento e as semelhanças das sociedades e suas diferenças.

O Jornalismo deriva da palavra Jornal que possui origem do latim. O dicionário Houaiss define Jornal como: substantivo masculino, do latim diurnális, relativo ao dia, diário, do francês journaliste (analista de um dia).

Tal área está condicionada a permear por diversos campos, seja do passado, do presente, com o foco em resgatar um conteúdo de essencial importância informacional para que sejam reproduzidos e se tornem conhecimento da sociedade. Essa permeação cria uma aproximação de outras ciências, como, por exemplo, a História.

O relacionamento entre Jornalismo e História, por exemplo, apresenta-se bastante profícuo para os dois ofícios. Como ponto de correlação entre as duas áreas o aspecto de pesquisa que os jornalistas fazem para apresentarem as raizes históricas dos fatos abordados.

Os jornalistas como produtores de Histórias imediatas nem sempre estão dispostos a investigar os fatos, em inúmeras construções é necessário recorrer a fontes históricas para interpretar o passado a fim de escrever sobre determinado assunto.

Quando se fala em "escrever a História" refere-se, sobretudo, aos momentos em que o Jornalismo ultrapassaria a simples missão de informar e passa a atuar como "uma entidade social e cultural, carregada de emoções, alimentando processos complexos de comunicação com informação, análises e opiniões que podem mudar os rumos de povos e nações" (CHAPARRO, 1994, p. 92).
Visto isto, é possível então, engendrar e perfazer um conhecimento mais rico e holístico. Possibilita então a união de informações emetodologias de vários âmbitos do saber para o mesmo fim.

\section{A Etnoistória como mediadora}

Ora, se a História permite esse entrelaçamento de conhecimento vindas de outras áreas, de que estudo estamos falando? Para Jorge Eremites (2003, p. 37-47), trata-se da Etnoistória, uma abordagem que é utilizada em várias fontes de estudo, porém ainda pouco compreendida.

A terminologia, para Trigger (1982), é uma abordagem que se utiliza de várias fontes de estudo, como a Arqueologia, a linguística histórica, a Antropologia, a Etnologia, as quais complementam os registros escritos.

Por outro lado, segundo o autor, no Honaiss (2001) a etnoistória é apresentada como um estudo "da História de um povo ou grupo social", ao passo que o dicionário Aurélio (apud TRIGGER, 1982) define-a como uma disciplina "que se dedica à reconstituição da História dos povos não-letrados", que se valem de fontes bastante variadas: orais, arqueológicas, linguísticas, textuais etc.

Diante de um arsenal de conceitos, onde em diferentes países a palavra ganha significados distintos, aqui no Brasil, como salienta Eremites de Oliveira (2005), os cientistas sociais, em especial os historiadores, parecem não ter muito claro o que seja a etnoistória, não raramente a confunde com o que, grosso modo, está convencionado a chamar de História Indígena. Dessa maneira, pode-se validar a significância de Etnoistória como uma metodologia interdisciplinar ou disciplina híbrida que utiliza dados arqueológicos, etnográficos, fontes textuais diversas, tradição oral, dentre outros, com o propósito de estudar a História dos povos indígenas, sobretudo a História dos contatos entre as sociedades nativas e os europeus e euroamericanos e suas mudanças socioculturais.

A Etnoistória como mediadora entre outras extensões de busca pelo conhecimento sugere fortemente a interdisciplinaridade. Uma interface em diversos campos de pesquisa, principalmente quando se trata da temática indígena.

Concomitantemente, dimensiona-se outra discussão; a associação da História indígena e Etnoistória e, novamente, autores como Jorge Eremites, aborda categoricamente. Ele afirma que 
os termos Etnoistória e História Indígena seriam utilizados como sinônimos é certo que o uso do primeiro implica em valer-se de um método em construção e de caráter interdisciplinar, cada vez mais sólido perante as interfaces entre a Antropologia e a História, dentre outros campos do conhecimento (EREMITES, 2003).

Os diálogos que possibilitam uma sincronia entre distintas ciências, a fim de engendrar uma conjectura coesa, precisa, verdadeira, inquestionável, irrefutável por acautelar-se de qualquer falha.

Quanto à obtenção da informação, podese analisar a forma com que os meios de comunicação muitas vezes utilizam, de maneira equivocada, metodologias e fontes históricas para contextualizar uma notícia, principalmente quando se trata da temática indígena. É necessário que se conheça profundamente a cultura, a crença, a religião e o modo de vida do povo noticiado, pois uma informação mal interpretada será fonte geradora de opinião de uma gama de pessoas, que não têm conhecimento o bastante para distinguir informações verídicas e de não verídicas.

A questão da demarcação de terras indígenas, por exemplo, deflagra uma subversão de informações, por isso, requer um profundo conhecimento. Quando esse tema é abordado devese levar em consideração que existem vários conflitos, desde as disputas de terra entre índios e não índios até o confinamento de várias etnias em uma mesma área, desencadeando um conflito cultural.

A etnia Kaiowá pode ser citada como exemplo quando se fala principalmente do processo de perda territorial e, consequentemente, confinamento em espaços extremamente exíguos de um contingente populacional. A resultante dessa interferência foi o comprometimento na economia desses povos indígenas. Este é apenas um, dos vários problemas, que surgem por causa da luta pelas terras.

Diante dessa situação, surgem as iniciativas indígenas pela retomada das terras, o que torna uma fonte inesgotável para a imprensa explorar, porém sem o conhecimento histórico antropológico dessas informações são defasadas pela falta de conhecimento.

Essas áreas de conflito ao serem retratadas pelos meios de comunicação requerem pesquisas minuciosas, principalmente do ponto de vista antropológico, pois existem algumas informações que são ocultadas como, por exemplo, o fato do Mato Grosso do Sul ser um estado onde os conflitos fundiários envolvendo índios e fazendeiros são corriqueiros. Porém existe um contexto histórico que é preciso dominar para interpretar e interligar os fatos. Observado esse pequeno demonstrativo percebe-se então que o enredo ganha uma conotação política para melhor compreensão do processo de dominação das terras.

\section{Em cena: o Jornalismo}

Ao entrar no universo indígena, o pesquisador-investigador ${ }^{1}$ se deparará com inúmeras informações que serão interpretadas. Porém, isso poderá ocorrer de duas maneiras, de maneira artificial; pode-se distorcer o real sentido do que se quer transmitir por não demonstrar um profundo conhecimento sobre determinadas áreas e, de maneira analítica; em que o pesquisador detém informações sobre a cultura, o ambiente e a crença.

Para chegar a certas conclusões sobre determinado assunto é preciso falar do uso das fontes históricas, um estudo do passado feito a partir de vestígios, testemunhos, documentos e monumentos de outras civilizações a fim de representar de maneira confiável os fatos que ocorreram. A utilização dessas fontes não é feita somente por meio da escrita, mas da observação de línguas, paisagens e edificações.

Neste momento conota-se a necessidade de se manter um relacionamento interdisciplinar, em que os profissionais das respectivas áreas possam complementar-se, somando seus conhecimentos acadêmicos e técnicos em prol da pesquisa a fim de garantir informações mais fieis.

Um assunto que gera bastante discussão, como já citado, é a questão indígena, em função das complexidades, por ter uma história abundante e distinta, sobretudo em razão da diversidade cultural que se consolida a medida que os grupos vão se identificando, escolhendo e assumindo seu modo de vida, pois não estão atrelados somente na ocupação territorial mas também pela identificação com o sistema social.

Cada etnia apresenta um modo de vida, uma religiosidade, uma crença, enfim, uma

\footnotetext{
1 Usaremos o termo pesquisador para a condição de jornalista.
} 
organização. Quando acontecimentos que ocorrem em tribos indígenas são retratados pelos meios de comunicação é comum encontrar alguns desencontros de informações.

Ou seja, o olhar, o ouvir e o escrever aliado ao conhecimento prévio sobre os povos e culturas ou a busca de informações em fontes seguras viabilizará uma notícia fidedigna.

Umas das questões levantadas por Eremites (2007) foi quanto à nomenclatura dos indígenas da região de Dourados. Segundo ele, são comuns erros relativos à nomenclatura das populações indígenas da região. Muitas vezes os nomes são confundidos entre as etnias Guarani, Kaiowá e Ñandeva. Muitos afirmam que algumas indígenas pertencem aos grupos guarani Kaiowá ou Guarani Nandeva demonstrando flagrantes imprecisos de nomenclatura.

Aos jornalistas, os redatores, e os repórteres que produzirão uma matéria sobre a temática indígena, seja ela em qualquer âmbito, faz-se necessário a análise das informações junto a fontes confiáveis, vez que estas matérias serão arquivadas, o que de certa forma, as cristaliza como legítima. Torna-se lamentável quando o texto, que passa a ser fonte, se apresenta confiável, sendo que a interpretação das informações foi feita de forma superficial.

A pesquisadora Cremilda Medina (2005, p. 34) afirma que no processo de decifração deve se ater a cuidados técnicos da apuração possível da verdade. O Jornalismo, por um lado, e as técnicas de trabalho das Ciências Humanas, por outro, possibilitam acúmulos de conhecimentos que dão respaldo a uma reportagem que tenta apurar os fatos e a rede de forças que atua sobre eles, ou seja, inevitavelmente, os caminhos irão se cruzar. "O Jornalismo, pela contingência da presentificação e da periodicidade, informa aproximações mais superficiais, sujeitas a erro".

Assim, os jornalistas precisam saber da necessidade de possuir conhecimentos históricos, em termos mais conceituais e metodológicos, a fim de que as investigações alcancem compreensões mais explicativas do que descritivas. Sobre a postura do entrevistador é importante ressaltar que ele não é um especialista. É, especializado na técnica de reportagem, na qual a entrevista ocupa espaço privilegiado e para aprofundar o assunto abordado procura respaldo em especialistas de várias correntes de informação e interpretação.
A região de Dourados pode servir como exemplo, por abrigar uma reserva indígena urbana composta por três etnias onde se falam variadas línguas.

Esse convívio, apesar da proximidade territorial, não compromete a preservação cultural de cada etnia. Há um resguardo cultural pautado pela autonomia. Caso não haja conhecimento de alguns termos, o sentido real pode ser deturpado e perderá toda a essência. Essa é a principal preocupação quanto ao uso das fontes históricas pelos jornalistas, para evitar conflito.

É importante destacar também que existem profissionais da comunicação comprometidos com a proposta de noticiar de maneira fidedigna e que, quando se estabelece um determinado dado ou assunto, o profissional de comunicação dever recorrer a historiadores e arqueólogos entre outros profissionais. Dessa maneira evitam-se alguns desencontros de informações.

Ao consultar outras áreas, a intenção vai além da produção de textos informativos, ela aspira por textos credíveis. Tal paradigma diz respeito à busca em ultrapassar a façanha da descrição dos fatos que ocorrem.

Assim, o uso das fontes históricas deve seguir critérios propostos pela área em que se desenvolve a pesquisa.

Nem sempre haverá documentos escritos sobre determinados povos, e mesmo que haja é preciso conferir o grau de confiabilidade, pois quanto mais antigos os vestígios e sem uma análise coerente, menor a possibilidade de conseguir quaisquer dados fornecidos por povos com escrita.

Outra ferramenta que pode ser utilizada são as fontes arqueológicas, "que devem serabordadas tendo em vista a possibilidade da analogia com outros povos em situação semelhante, no que é chamado de paralelo etnográfico" (FUNARI, 2007).

Ou seja, a partir da observação da maneira em que comportam os povos vivos fazse um comparativo em busca de semelhanças no modo de vida, os artefatos, o modo em que foram criados, enfim, até chegar a um conceito dos povos do passado.

\section{CONCLUSÃO}

Ao iniciar este artigo, a intenção foi relatar a importância de transitar-se por outras áreas, a fim de ampliar o conhecimento. Dito de outra 
forma, a proposta parte da interdisciplinaridade das áreas de Arqueologia, História e Jornalismo em prol de informações verídicas.

O motivo de utilizar essas esferas se deu pelo fato de que os campos se assemelham quanto às estratégias de pesquisa, então, porque não estreitar esse relacionamento, principalmente o Jornalismo, que sempre recorre a fontes históricas, antropológicas e até mesmo arqueológicas a fim de elucidar ou produzir uma matéria jornalística.

A partir desta conjectura, é possível recorrer à etnoistória, uma abordagem que se utiliza de várias fontes de estudo, porém ainda pouco compreendida. A etnoistória é tida como mediadora entre outras extensões de busca pelo conhecimento, pois ela sugere fortemente a interdisciplinaridade, a interface em diversos campos de pesquisa, principalmente quando se trata da temática indígena.

Mesmo que exista este relacionamento aberto, ainda é possível constatar que inúmeros profissionais da área de comunicação utilizam terminologias de maneira equivocadas, por simplesmente não conhecerem o contexto a que pertencem e quais os significados que ganham, como por exemplo, o uso incoerente das nomenclaturas relacionadas às étnicas Guarani, Kaiowá e Ñandeva.

Pode-se dizer então, da necessidade de permear por campos referentes aos assuntos abordados para que a interpretação desses dados seja feita de maneira confiável, mas que muitas vezes, esse diálogo é dispensado pela falta de tempo.

Portanto, não é valido somente recorrer a essas áreas e sim, saber utilizá-las.

De modo geral, compreender o processo de interpretação já que não parte somente e simplesmente de uma decodificação superficial, essa visão vai além, ultrapassa anos e anos, décadas e décadas, séculos e séculos e as mudanças ocorridas com o passar do tempo são geradores de novas abordagens teóricas que muitas vezes apenas profissionais imbuídos nos estudos de forma comprometida são capazes de interpretar.

\section{REFERÊNCIAS}

BRASIL, A. C. Telejornalismo, internet e guerrilha tecnológica. 2. ed. Rio de Janeiro: Ciência Moderna, 2002. v. 1.

CHAPARRO, M. C. Pragmática do jornalismo. São Paulo: Summus, 1994.

MEDINA, C. C. de A. O diálogo possível da entrevista. 4. ed. São Paulo: Ática, 2005.

EREMITES DE OLIVIERA, J. Cultura material e identidade étnica na arqueologia brasileira: um estudo por ocasião da discussão sobre a tradicionalidade da ocupação kaiowá da Terra Indígena Sucuri'y. Revista de Arqueologia, Belém, v. 19, p. 29-50, 2007.

Sobre os conceitos e as relações entre história indígena e etnoistória. Prosa, Campo Grande, v. 3, n. 1, p. 39-47, 2003.

EREMITES DE OLIVIERA, J.; SILVA, C. A. da. Fontes textuais e etnoistória: possibilidade de novas abordagens para uma história indígena no Estado do Tocantins. Revista do Museu Antropológico, Goiânia, v. 8 , n. 1, p. 77-84, 2005. Disponível em: <http:// cleubesilva.blogspot.com/>. Acesso em: 30 jun. 2008.

FUNARI, P. P. Como se tornar arqueólogo no Brasil. Boletín de Antropología Americana, São Paulo, v. 44, p. 74-85, 2000.

Teoria e arqueologia histórica: a América Latina e o mundo. Vestígios, v. 1, p. 49-56, 2007.

HOUAISS, A. Dicionário Houaiss da língua portuguesa. Rio de Janeiro: Objetiva, 2001.

OLIVEIRA, C. R. O trabalho do antropólogo. 2. ed. São Paulo: Ed. da UNESP, 2005.

TRIGGER, B. G. Etnohistoria: problemas y perspectivas. Traducción de Catalina Michieli. Ethnohistory, v. 29, n. 1, p. 1-19, 1982.

Recebido: 03/03/2009

Received: 03/03/2009

Aprovado: 16/03/2009

Approved: 03/16/2009

Revisado: 30/10/2009

Reviewed: 10/30/2009 